\title{
CONSTRUÇÃO VERDE: EMPREGO DE RECURSOS RENOVÁVEIS NA CONSTRUÇÃO CIVIL
}

\author{
GREEN CONSTRUCTION: USE OF RENEWABLE RESOURCES IN CIVIL \\ CONSTRUCTION
}

\author{
Wagner Oliveira Severiano Junior ${ }^{1}$
}

RESUMO: A problemática da sustentabilidade na construção civil adquiriu um papel central na reflexão em torno das dimensões do desenvolvimento e das alternativas que configuram para garantir uma qualidade de vida, economia, matéria-prima, mão de obra, meio ambiente, de forma harmoniosa. Uma construção que busca ser sustentável usa materiais locais, reciclados e reutilizáveis. Assim como recursos renováveis não só nos processos de execução da obra, mas como no seu funcionamento. Este artigo tem como objetivo geral analisar oportunidades e apresentar contribuições para a prática sustentável na construção civil a partir de recursos renováveis. $O$ método utilizado para a coleta de dados foi o de pesquisa científica em anais e periódicos, além de livros e artigos, e o critério adotado para a seleção de amostras foi o da Escolha Racional. A partir da análise qualitativa e quantitativa dos dados, foram identificadas contribuições para a sustentabilidade e recursos renováveis, que podem ser implementadas por empresas que atuam no setor da construção civil.

Palavras-chave: Sustentabilidade. Construção civil. Recursos renováveis.

ABSTRACT: The problem of sustainability in civil construction has taken a central role in the reflection around the dimensions of development and the alternatives they configure to ensure a quality of life, economy, raw material, labor, environment, harmoniously. A building that seeks to be sustainable uses local, recycled and reusable materials. As well as renewable resources not only in the processes of execution of the work, but as in its operation. This article has as its general objective to analyze opportunities and present contributions to sustainable practice in construction from renewable resources. The method used for data collection was scientific research in the annais and journals, in addition to books and articles, and the criterion adopted for the selection of samples was that of Rational Choice. From the qualitative and quantitative

\footnotetext{
${ }^{\text {I }}$ Formado em Engenharia Civil pela Universidade Anhanguera de São Paulo(UNIAN-SP), especializado em Gestão de Projetos e em Gestão Estratégica de Negócios, ambas pela Universidade Anhembi Morumbi. Técnico em Mecatrônica pela ETEC Julio de Mesquita e curso de aprendizagem industrial (CAI) na área de Eletroeletrônica pelo SENAI A. Jacob Lafer. Cursando técnico em Meio Ambiente pela ETEC Julio de Mesquita. Atualmente desenvolve linha de pesquisa voltada para a Construção Civil na área de Sustentabilidade e Meio Ambiente buscando integrar recursos renováveis nos processos e métodos construtivos na esfera da Engenharia. E- mail: engcivil.wagner.oliveira@gmail.com.
} 
analysis of the data, contributions to sustainability and renewable resources were identified, which can be implemented by companies operating in the construction sector.

Keywords: Sustainability. Civil Construction. Renewable resources.

\section{Introdução}

Nos dias atuais, assiste-se a uma crescente conscientização da sociedade da finitude dos recursos naturais, da necessidade de práticas de menor impacto ambiental, e da busca de um modelo de desenvolvimento que se sustente. Prezando pela manutenção e/ou melhoria da qualidade de vida, esse modelo deve vir acompanhado de soluções de maior eficiência no uso dos recursos naturais, de menor impacto ambiental e de justiça social, pautadas em valores éticos.

Os impactos gerados pela construção civil estão basicamente relacionados ao consumo de recursos naturais e de energia e à geração de resíduos. Estes ocorrem tanto durante e para a construção quanto no uso de edifícios.

No Brasil, a Indústria da Construção Civil apresenta um quadro de atraso quanto à responsabilidade socioambiental, que se revela, por exemplo, nos investimentos pouco expressivos na formação e qualificação dos profissionais e na destinação inadequada dos resíduos sólidos, além de métodos e processos ineficientes.

A necessidade de integração dos recursos renováveis às construções requer cuidado, mas acima de tudo planejamento estratégico, visando harmonia entre o empreendimento e o meio ambiente. Partindo desse princípio, a utilização de energia renovável tornaria a construção sustentável, além de contribuir para a eficiência energética do empreendimento.

No que se refere à Indústria da Construção Civil, o setor é responsável por cerca de 60\% dos resíduos sólidos lançados nos centros urbanos brasileiros (ABRELPE, 2006), além dos desperdícios resultantes de seus processos construtivos, em torno de $25 \%$.

As fontes renováveis de energia localizadas nas áreas urbanas podem fazer uma contribuição importante no atendimento às necessidades energéticas das cidades e paralelamente aumentar a resiliência energética, mantendo o valor econômico dentro das comunidades urbanas.

Neste trabalho, adotou-se o modelo de pesquisa qualitativa e quantitativa. Qualitativa, por se tratar de uma pesquisa bibliográfica sobre responsabilidade socioambiental na construção civil, com a proposta de adequar o processo construtivo de 
um empreendimento à nova realidade do mercado; e quantitativa quanto a forma de tratamentos dos dados, considerando a análise dos resultados da pesquisa.

\section{DESENVOLVIMENTO SUSTENTÁVEL}

Nosso modelo de desenvolvimento é caracterizado pelo alto consumo de recursos naturais e pela degradação ambiental. As limitações de quantidade de recursos naturais e as mudanças ambientais e climáticas decorrentes dessas características mostram que esse quadro é insustentável. A consciência da necessidade de um novo modelo de desenvolvimento que busque a sustentabilidade se mostra cada vez mais presente na sociedade.

O setor de construção civil, visto como agente produtor dos ambientes construídos, é essencial nesse novo paradigma, devendo adotar novas práticas baseadas em conceitos coerentes com a sustentabilidade. O surgimento do conceito de desenvolvimento sustentável veio da percepção dos problemas oriundos do avanço da nossa civilização. Tais problemas possuem escala global. Portanto, apesar da busca de ações locais direcionadas a sustentabilidade, deve-se sempre ter no horizonte a relação com o processo global.

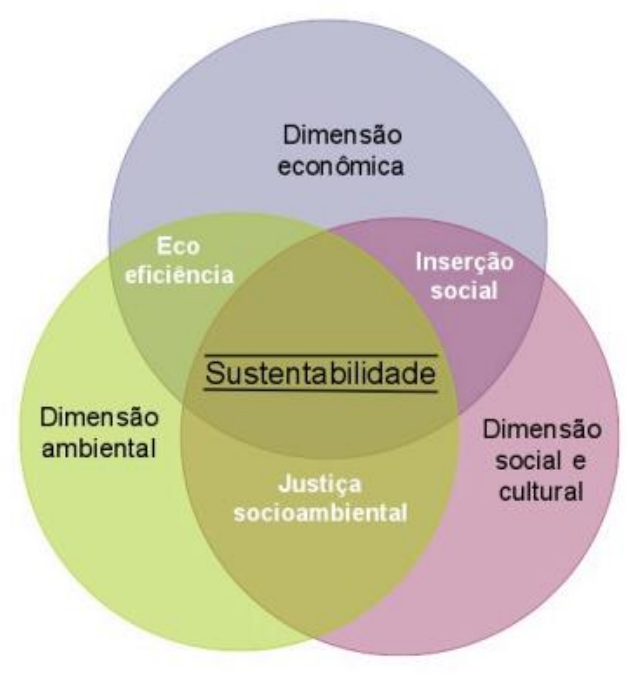

Figura I: Dimensões da sustentabilidade (ELKINGTON, 1994).

É necessário que a sociedade adote um papel fundamental diante de todas as mudanças climáticas que vem ocorrendo ao passar dos anos em consequência de seus atos danosos ao meio ambiente. O desenvolvimento de uma consciência ecológica se faz cada 
vez mais requerida uma vez que entendemos que nossos recursos são finitos e, portanto, nossa exploração dos mesmos resultará em um futuro catastrófico.

Uma construção sustentável, por sua vez, é aquela comprometida com o desenvolvimento sustentável. Seus conceitos e práticas são usualmente relacionados a ações e metas previstas nos meios decisórios do desenvolvimento sustentável, devendo ser uma resposta a estas. As Agendas 2I, incluindo a definida pela ONU e as diferentes iniciativas nacionais, regionais, locais e setoriais, são o principal meio decisório destas ações e metas. E estas são normalmente entendidas a partir da integração das dimensões ambientais, sociais e econômicas.

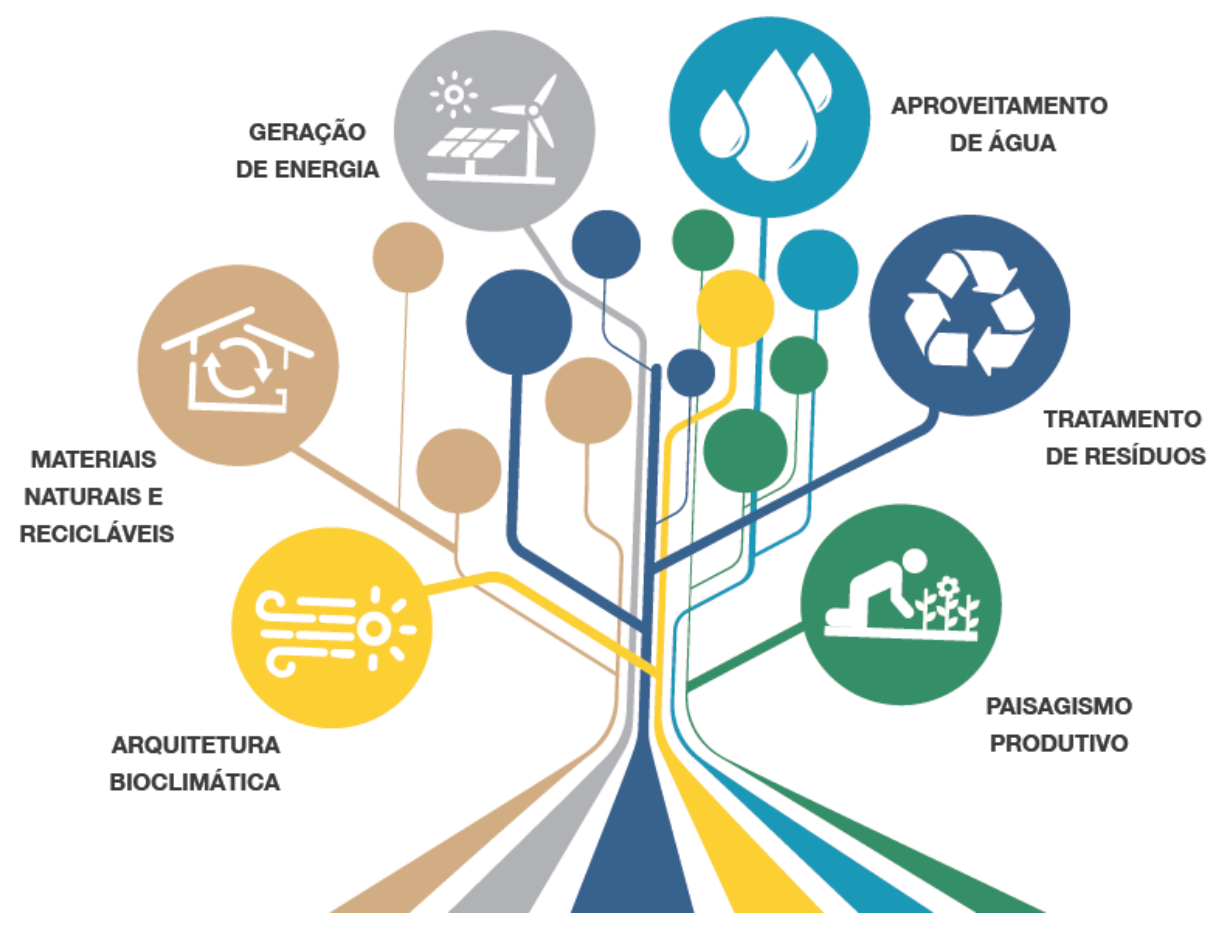

Figura 2: Principais práticas sustentáveis para o setor da Construção Civil (Ecoeficientes, 2015).

Uma gestão ambiental também se faz necessária, sendo uma questão de sobrevivência, tendo em vista que o meio ambiente é hoje parte do processo produtivo e não mais uma externalidade. Isto faz com que a variável ambiental esteja presente no planejamento das empresas por envolver a oportunidade de redução de custos, já que uma empresa poluente é, antes de tudo, uma entidade que desperdiça insumos e gasta mais para produzir menos.

A avaliação do impacto ambiental é considerada um instrumento de política ambiental preventivo, pois pretende identificar, quantificar e minimizar as consequências 
negativas sobre o meio ambiente antes que o empreendimento inicie suas atividades. $O$ Conselho Nacional do Meio Ambiente (CONAMA), através de resoluções e outros documentos legais, estabelece diretrizes para a gestão ambiental no Brasil.

Os impactos gerados pela construção civil estão basicamente relacionados ao consumo de recursos naturais e de energia e à geração de resíduos. Estes ocorrem tanto durante e para a construção quanto no uso de edifícios. A discussão de conceitos de concepção de edifícios com menor consumo de recursos naturais, de energia e menor geração de resíduos, contribui para uma prática de sustentabilidade na medida em que soluções são criadas e que se aumenta o nível de conscientização da sociedade para o problema. Pesquisas sobre esses conceitos e possíveis soluções têm papel fundamental na mudança de paradigma do setor da construção civil.

A incorporação de práticas de sustentabilidade no edifício é uma forma de promover a busca pela igualdade social, valorização dos aspectos culturais, maior eficiência econômica e menor impacto ambiental nas soluções adotadas nas fases de projeto, construção, utilização, reutilização e reciclagem da edificação, visando à distribuição equitativa da matéria-prima e garantindo a competitividade do homem e das cidades.

\section{OBJETIVOS}

Os objetivos gerais deste artigo são propor um conceito teórico da sustentabilidade nos empreendimentos de construção civil baseado na síntese dos conhecimentos existentes sobre as características fundamentais da sustentabilidade, e construir um modelo de aplicação deste conceito coerente com as características passíveis de serem testadas. Para tal, o trabalho tem como objetivos específicos:

- Discutir a situação atual da sustentabilidade na construção civil através do estudo do panorama atual dos conceitos de sustentabilidade relacionados ao nosso modelo de desenvolvimento econômico;

- Discutir o panorama atual dos conceitos de sustentabilidade na construção civil e das práticas de sustentabilidade já adotadas nos empreendimentos de construção civil;

- Estudar os métodos gerais que promovam uma síntese de conhecimentos e métodos que permitam uma abordagem holística do assunto;

- Apresentar fundamentação para a aplicação de recursos renováveis na construção. 


\section{RECURSOS RENOVÁVEIS NA CONSTRUÇÃO CIVIL}

Os recursos naturais renováveis têm um papel importante no desenvolvimento tecnológico sustentável. O conceito consiste em recursos naturalmente reabastecidos como sol, vento, chuva, dentre outros, utilizados de maneira inteligente e eficaz para suprir necessidades humanas nos mais diversos setores.

O setor de construção civil é fundamental para o desenvolvimento do país. A prova disso é que esse mercado é apontado como um dos principais fatores responsáveis pelo crescimento econômico. Por outro lado, a construção civil é tida como uma das áreas de maior impacto negativo quando o assunto é o meio ambiente.

Isso acontece por diversas razões, entre elas está a geração de resíduos, o alto consumo energético de fontes poluentes pelos maquinários, o desperdício de água, a poluição e o desperdício de materiais.

Dentro desse contexto, as energias renováveis, em especial a energia solar, estão sendo vistas cada vez mais com bons olhos. Os sistemas fotovoltaicos podem ser grandes aliados na diminuição dos impactos ambientais provenientes da construção civil.

$\mathrm{Na}$ construção civil, por exemplo, foi estabelecido uma cota mínima para a utilização de energia renovável. Hoje o setor é responsável por um consumo considerável de fontes de energia renovável, seja ela na utilização dos empreendimentos ou utilizadas em seus processos na fase de execução, porém visto de um panorama geral, não apresenta participação significativamente grande.

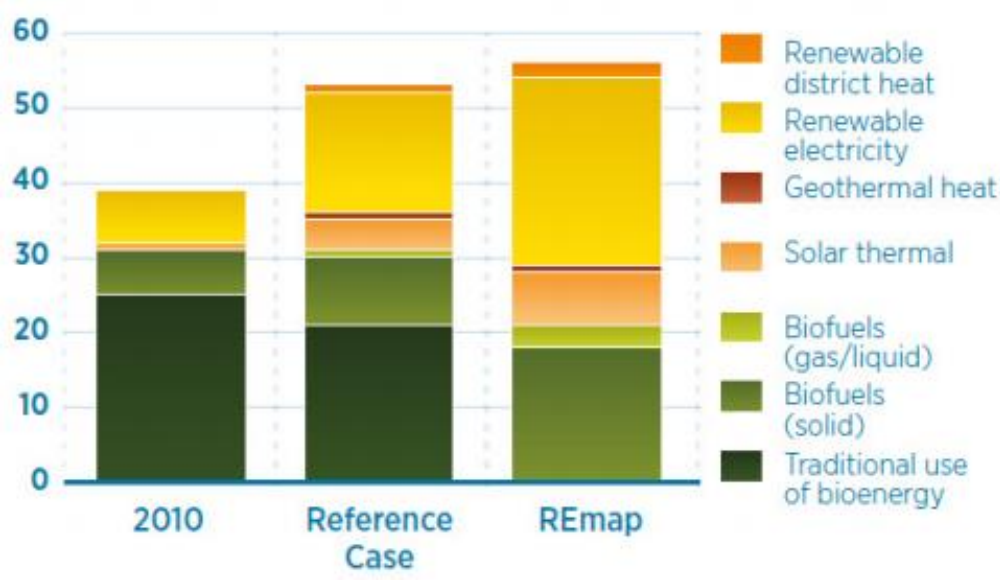

Figura 3: Consumo de fontes renováveis de energia no setor de edificações, em EJ/ano (IRENA, 2016). 
Em se tratando da energia solar, esta tem muito a agregar à construção civil, tanto com a execução de obras mais sustentáveis e econômicas quanto pelo maior valor agregado de imóveis que contam com o próprio sistema fotovoltaico. Sua eficiência seria maior nas cidades menores, em função da baixa densidade, mas por outro lado as grandes cidades estariam mais preparadas para materializar esse potencial. Um requisito fundamental para se atingir essa meta seria a integração de sistemas de serviços de energia distribuídos nas cidades, o que inclui infraestrutura de energia urbana mais inteligente e estímulos a novos modelos de negócio.

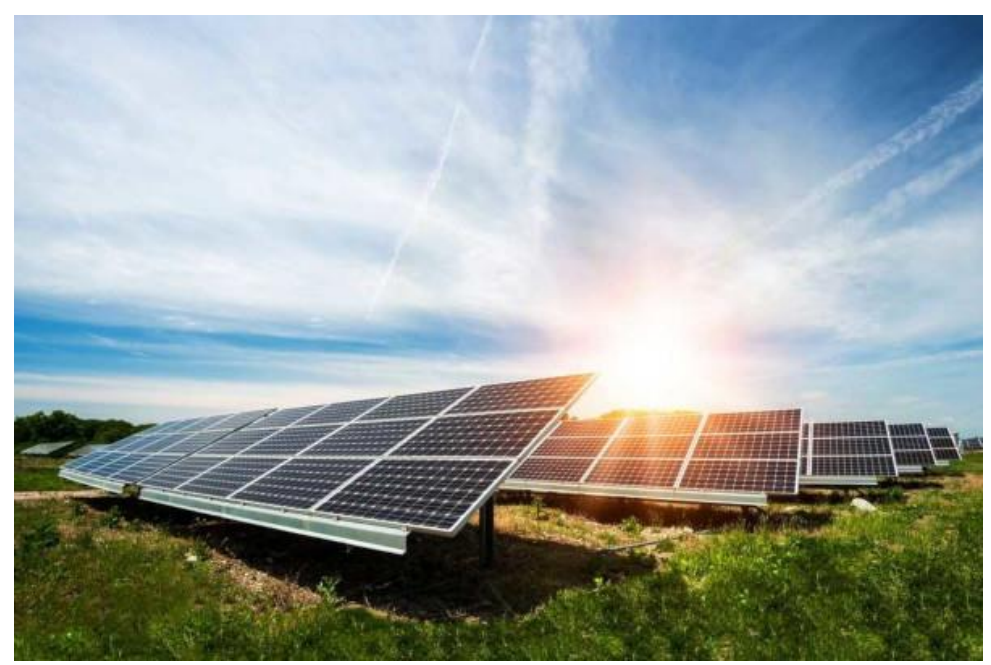

Figura 4: Placas de painéis fotovoltaicos (Brasil Escola, 2018).

Ao reduzir o impacto ambiental e social na construção civil, fica mais fácil atingir um posicionamento favorável para identificar novas oportunidades de aperfeiçoar o trabalho e diminuir despesas.

Boas práticas ambientais e sociais também otimizam a imagem corporativa de uma empresa. Para fins de comunicação com seus públicos, é possível fazer uso de ferramentas baseadas no marketing verde.

Existem várias formas de aplicar a energia solar na construção civil, reduzindo custos e impactos ambientes provenientes do uso da energia elétrica. O melhor de tudo é que não são apenas as novas edificações que podem contar com esse tipo de tecnologia. Construções antigas também estão inseridas nesse contexto.

$\mathrm{Na}$ construção civil, a água reutilizada é dividida em três grupos: águas cinzas, águas negras e águas pluviais. As águas negras são as provenientes dos vasos sanitários. O grupo 
das águas cinzas se divide em águas cinzas claras (provenientes de chuveiros, banheiras, lavatórios e máquinas de lavar roupas) e águas cinzas escuras (provenientes de pias de cozinha e máquinas de lavar pratos). As águas pluviais são as águas provenientes das chuvas, as quais, são captadas por ralos ou calhas na cobertura das edificações.

O tratamento e reuso da água cinza é uma das formas de minimizar o problema iminente da escassez de água em áreas urbanas. Após seu tratamento, esta água pode ser reutilizada em diferentes fins, reduzindo de 30 a 60\% o requerimento por água potável em uma edificação.

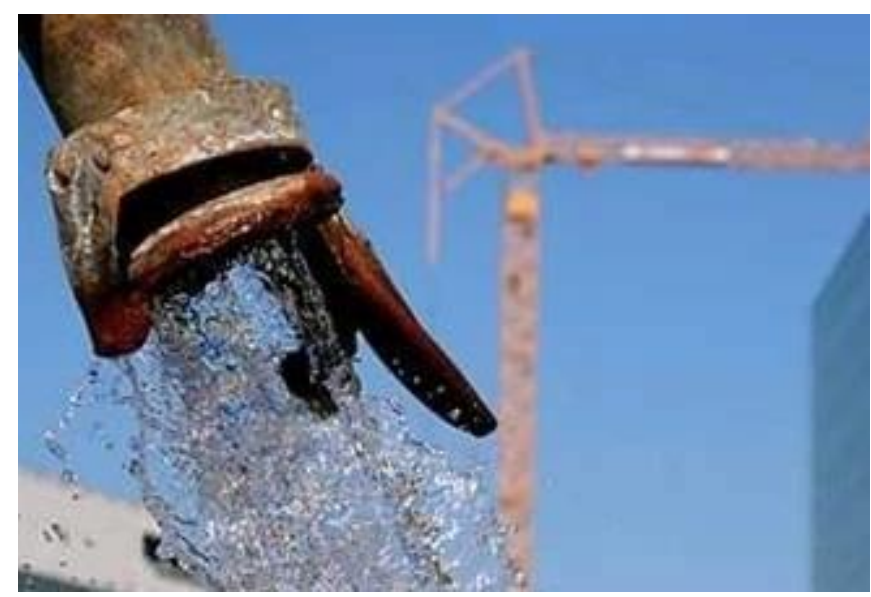

Figura 5: Torneira com fluxo de água (Flush Engenharia, 2017).

O reuso da água cinza no canteiro de obras pode gerar economia de 30\% a 50\% do consumo e ainda reduzir a produção de esgoto, medida importante para áreas onde não há sistema de tratamento.

Além disso, há a possibilidade de usar água de reuso, o que apresenta uma economia de até 50\% no consumo de água do empreendimento, usando-a para zeladoria como lavagem ou nos jardins, além de descargas de sanitários de uso social. A utilização desse recurso auxilia de forma significante para o consumo hídrico, além da preservação ambiental e a diminuição da pegada hidrológica.

O consumo e a gestão eficiente da água são um dos requisitos mais importantes para o desenvolvimento de edifícios verdes, especialmente para aqueles que buscam a constatação de uma certificação sustentável.

Outro fator fundamental que basicamente se faz crucial para a sustentabilidade da construção civil é a gestão correta dos resíduos sólidos oriundos dos processos de 
construção. Por ser um dos setores de maior geração, é imprescindível o olhar focado para sua gestão.

Apesar de causar tantos problemas, o entulho deve ser visto como fonte de materiais de grande utilidade para a construção civil. Seu uso mais tradicional - em aterros - nem sempre é o mais racional, pois ele serve também para substituir materiais normalmente extraídos de jazidas ou pode se transformar em matéria-prima para componentes de construção, de qualidade comparável aos materiais tradicionais.

Um dos desafios é incorporar práticas que garantam maior durabilidade e menor consumo energético. A falta de gerenciamento deste resíduo gera desperdício, considerando que para a obra teve um custo financeiro e ambiental. Por isso, é importante conhecer os resíduos que são gerados na sua obra, para evitar prejuízos.

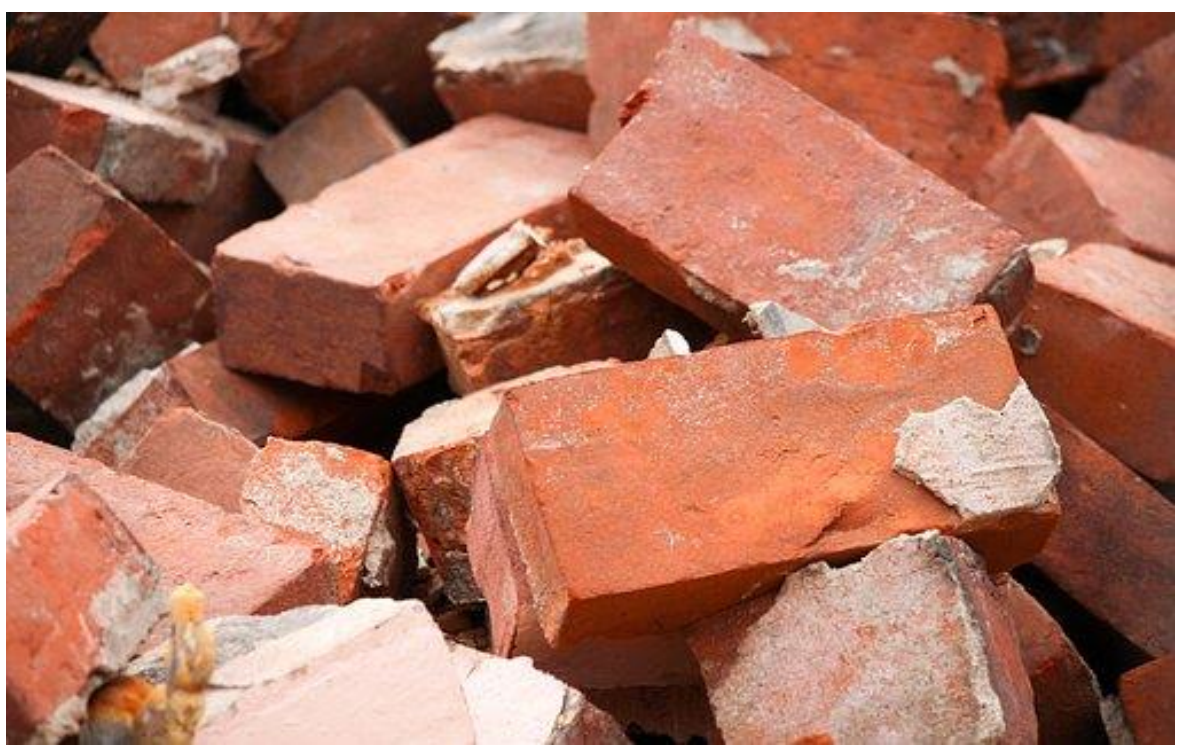

Figura 6: Resíduo sólido oriundo da construção (VG Resíduos, 2018).

Apenas $30 \%$ do entulho produzido em obras recebem um destino adequado, sendo que $95 \%$ dele poderia ser reciclado e incorporado nos processos de construção, o que implicaria em uma redução do custo da obra de até 50\%.

Além disso, os entulhos não podem ser descartados de forma convencional, para isso em algumas cidades brasileiras existem pontos para recolhimento para que tenham o destino correto. Basicamente, a reciclagem é realizada pela: triagem, trituração e classificação dos materiais. 


\section{SOLUÇÕES PRÁTICAS PARA A CONSTRUÇÃO CIVIL}

O Conselho Brasileiro de Construção Sustentável (CBCS) junto a Associação Brasileira dos Escritórios de Arquitetura (AsBEA), desenvolveram uma série de práticas para a sustentabilidade na construção como aproveitamento de condições naturais locais, como iluminação, por exemplo. Além disso, é de conhecimento público que todas as fases do ambiente construído devem apresentar conceitos sustentáveis, desde a idealização até o final da vida útil do empreendimento.

O potencial dos painéis fotovoltaicos vem sendo discutido incessantemente por se tratar de recursos tecnológicos que têm sido cada vez mais implantados em edificações que buscam unir eficiência e sustentabilidade. Juntamente a outras condutas de Green Building, a energia solar na construção civil é destaque como vantagem competitiva nesse setor.

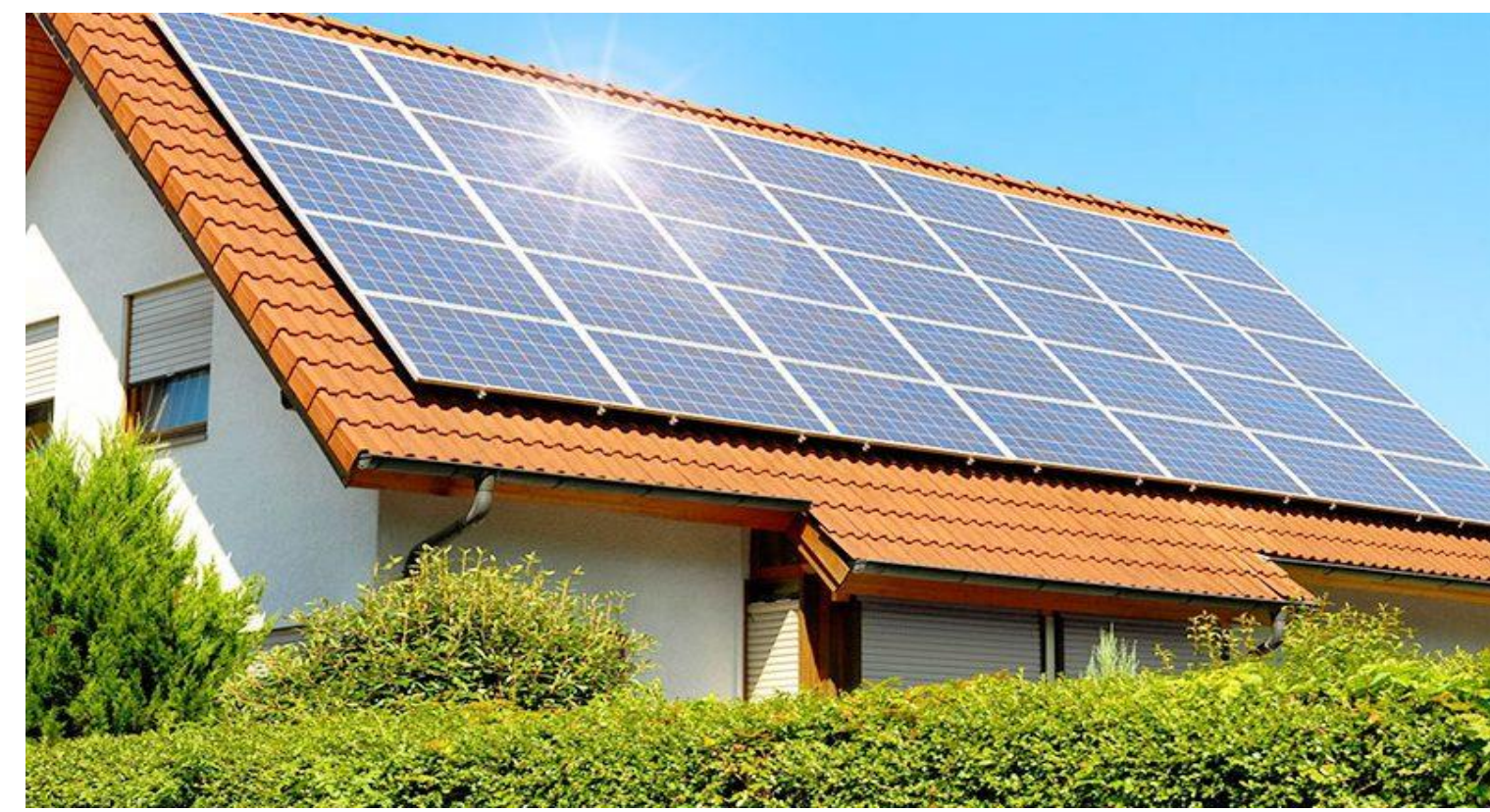

Figura 7: Telhado com placas fotovoltaicas (Boreal Solar, 2016).

O coletor solar é capaz de aquecer a água tanto de piscinas como pra usar em casa. A temperatura é definida pelo consumidor, de acordo com a utilização determinada.

Além disso, um sistema de energia fotovoltaica tem a capacidade de abastecer totalmente a demanda elétrica de um empreendimento. Equipamentos conectados à rede, quando projetados corretamente, pagam apenas o custo de disponibilidade da distribuidora local. 
Se a geração de energia solar ficar acima da demanda do imóvel, ainda existe a possibilidade de injetar o excedente na rede da concessionária. Isso gera créditos solares, que podem ser usados no prazo de 6o meses por todos os imóveis de mesma titularidade, atendidos pela mesma distribuidora de energia.

Além disso, ao captar água pluvial proveniente das chuvas, a mesma pode ser utilizada na descarga sanitária, na irrigação de jardins ou para benfeitorias da zeladoria, como a limpeza de áreas sociais. Caso a água não potável seja procedente de água cinza, a utilização não requer cuidados.

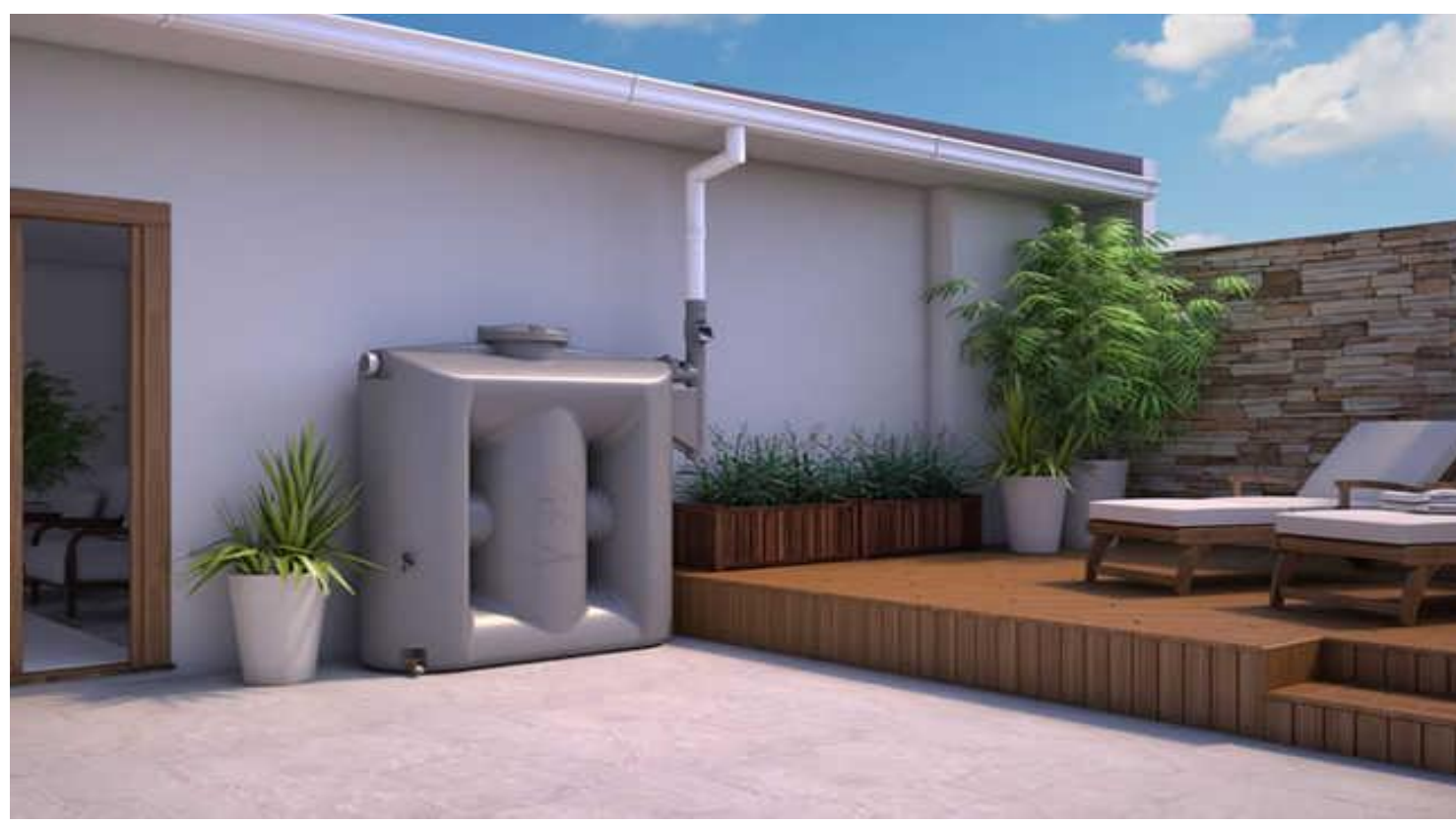

Figura 8: Sistema de captação de água pluvial (eCycle, 2015).

O sistema para aproveitamento da água de chuva tem baixo custo de implantação e operação. Além disso, diminui a demanda de água tratada e ajuda na prevenção de enchentes, por retardar o escoamento para a rede de drenagem.

Também apresenta baixo consumo de energia e fácil instalação, e oferece simplicidade operacional. É uma solução muito indicada para edifícios residenciais e comerciais, casas e empreendimentos sem acesso à rede de abastecimento e indústrias.

No que se refere a utilização de resíduos sólidos reciclados como produtos finais, é possível aplicá-los com a finalidade estética, além de poder incorporar em jardins ou até mesmo nos processos construtivos como agregado miúdo no concreto. 


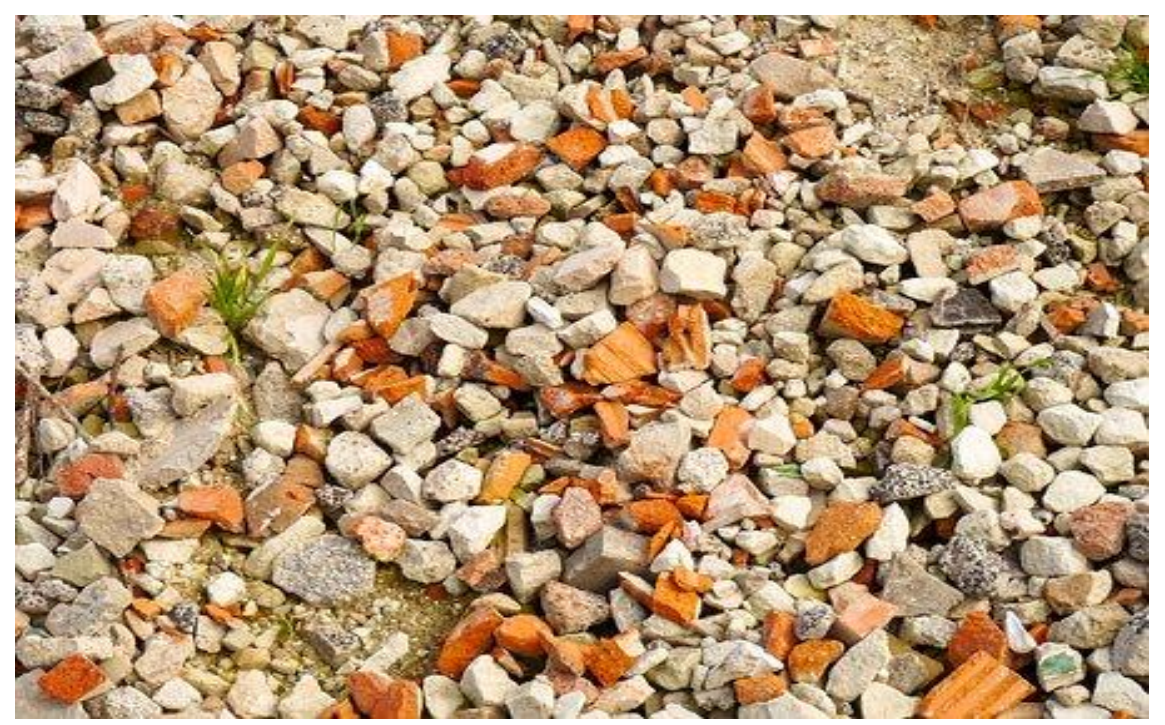

Figura 9: Entulho triturado (VG Resíduos, 2018).

É possível também produzir agregados - areia, brita e bica corrida para uso em pavimentação, contenção de encostas, canalização de córregos, e uso em argamassas e concreto. Da mesma maneira, pode-se fabricar componentes de construção - blocos, briquetes, tubos para drenagem, placas.

As prefeituras devem iniciar a implantação de um programa fazendo um levantamento da produção de entulho no município, estimando os custos diretos e indiretos causados pela deposição irregular. Com base nestas informações será possível determinar a tecnologia a ser empregada, os investimentos necessários e a aplicação dos resíduos reciclados.

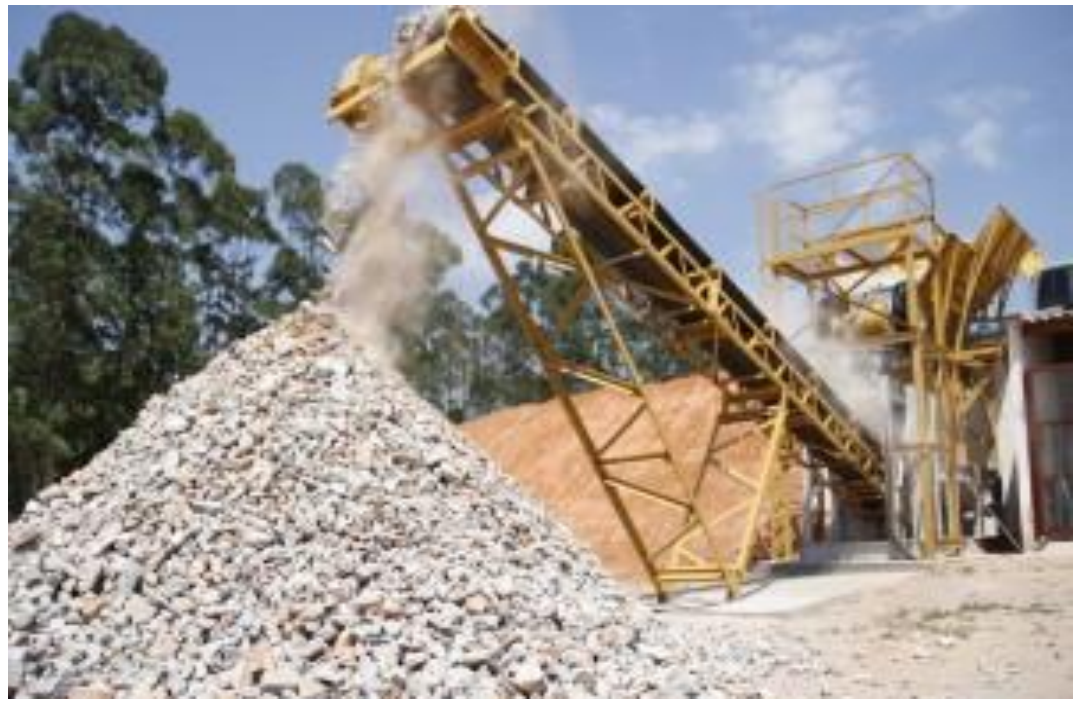

Figura ro: Máquina utilizada na reciclagem de entulho (Google, 202I). 
Grandes pedaços de concreto podem ser aplicados como material de contenção para prevenção de processos erosivos na orla marítima e das correntes, ou usado em projetos como desenvolvimento de recifes artificiais. $\mathrm{O}$ entulho triturado pode ser utilizado em pavimentação de estradas, enchimento de fundações de construção e aterro de vias de acesso.

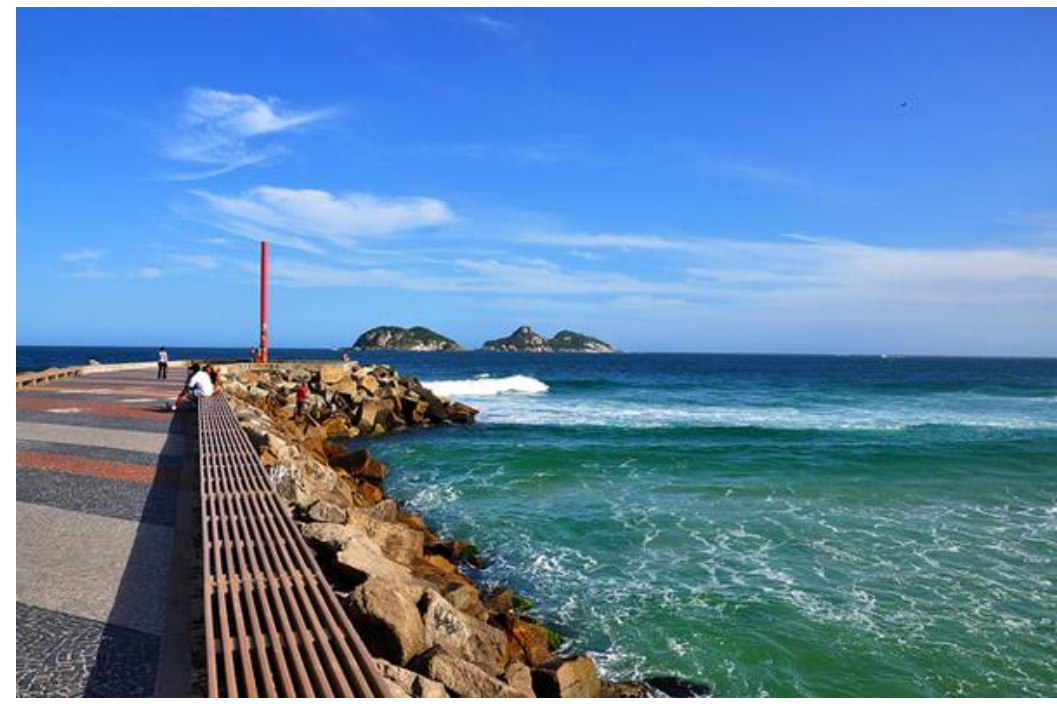

Figura II: Quebra mar da praia da Barra (Rio de Janeiro, 2018).

Entulho reciclado demonstra um potencial enorme e apresenta grandes benefícios para a indústria da construção civil por se tratar de um material residual abundante oriundo dos processos construtivos.

\section{CONCLUSÃO}

Em suma, no que se refere aos recursos renováveis apresentados disponíveis para a sociedade e que possivelmente podem se tornar parte fundamental dos métodos e processos adotados no setor da construção, foi apresentado de forma consistente inúmeros fatores que demonstram sua versatilidade assim como a eficácia de sua aplicabilidade. Relacionando com métodos e processos, antes amplamente difundidos, os recursos renováveis apresentam grandes vantagens de curto, médio e longo prazo.

No que tange a questão da viabilidade econômica, esta ainda encontra resistência por conta da indústria, no modo geral, porém é algo extensivamente estudado de forma que reduza os custos tendo em vista os benefícios anteriormente apresentados. Por se tratar de uma solução relativamente recente, mão de obra especializada tanto na idealização quanto 
na execução dos processos é de suma importância, garantindo não só a qualidade do projeto, como sua segurança.

Além disso, as edificações podem contribuir significativamente para descarbonizar as cidades através do uso de fontes renováveis de energia para aquecimento/resfriamento, cocção e nos eletrodomésticos, fazendo uso das aplicações mais difundidas de energia renovável em edifícios urbanos, os painéis solares fotovoltaicos e aquecedores de água solares. E outrossim, a utilização da água oriunda da chuva, pode ajudar não só no racionamento de água potável, mas também no balanço financeiro do empreendimento, uma vez que irá afetar de maneira significativa os gastos.

No que se refere os resíduos sólidos oriundos dos processos construtivos da indústria, é necessário que os órgãos de fiscalização responsáveis pelo setor estabeleçam medidas e normas mais efetivas e claras para a gestão dos mesmos, uma vez que o setor da construção civil é um, senão o maior, gerador residual. Foi apresentado inúmeras aplicações viáveis e cabíveis para tal, de forma que seja reciclada quase que ioo\%.

Portanto, é recomendando que governos nacionais e regionais desenvolvam códigos de energia rigorosos e exequíveis para as construções e critérios de desempenho para as

edificações novas e existentes, além de viabilizar incentivos políticos e financeiros efetivos para alavancar ações agressivas de eficiência energéticas nas construções e assim estabelecer uma demanda de mercado. Há algumas certificações nacionais e internacionais que legitimam e dão aval para as instituições no que se refere a sustentabilidade, de modo a mostrar o comprometimento das mesmas para uma questão tão largamente preocupante.

Também se faz necessário a viabilização de programas educativos, o reforço das capacidades existentes e melhoramento na resolução dos dados energéticos das edificações para ajudar a informar e melhorar a concepção, adoção e aplicação da política e finalmente promover as edificações energia-zero ou muito próximo disto.

\section{REFERÊNCIAS BIBLIOGRÁFICAS}

ANDERY, P. R. P.; VIEIRA, M. P. C. Dificuldades e Estratégias para Sustentação dos Programas de Garantia da Qualidade na Construção Civil Brasileira. Simposio Iberoamericano sobre Calidad y Competitividad en las Construcciones, Cuba, 2002. 
AGENDA 2I brasileira: ações prioritárias. Comissão de Políticas de Desenvolvimento Sustentável e da Agenda 2i Nacional. 2. Ed. Brasília: Ministério do Meio Ambiente, 2004. $158 \mathrm{p}$.

ANTUNES, Julianna. A Sustentabilidade na Construção Civil. Disponível em: 〈http://www.administradores.com.br/artigos/economia-e-financa/a-sustentabilidade-naconstrucao-civil/36112/>. Acesso em: 25 mai. 2021.

BAITELO, RICARDO. A caminho da sustentabilidade energética: Como desenvolver um mercado de renováveis no Brasil. São Paulo, Greenpeace, 2008.

BRAGA, Benedito et al. Introdução à Engenharia Ambiental. 2. Ed. São Paulo: Pearson Prentice Hall, 2005. 318p.

CÂMARA DA INDÚSTRIA DA CONSTRUÇÃO. Guia de Sustentabilidade na Construção. Belo Horizonte: FIEMG, 2008 6oP.

CBIC. Energia nas Construções: uma contribuição do setor à redução de emissões e de uso de fontes renováveis de energia. Brasília, 2017.

CBIC. Gestão Eficiente da Energia na Indústria da Construção - Energia Solar Fotovoltaica em Condomínios Oportunidades, Aplicações e Boas Práticas. Câmara Brasileira da Indústria da Construção. Brasília: CBIC, 2016.

CRAVEN, D. Sustainnable building: A Victorian Governament Perspective. Gaia Conference, 2006.

FLUSH Engenharia. Reuso de Água na Construção Civil. Disponível em: < https://www.flushengenharia.com.br/reuso-de-agua-na-construcao-civil〉. Acesso em: 27 mai. 2021. 
HINRICHS, Roger; KLEINBACH, Melin. Energia e meio ambiente. 3. Ed. São Paulo: Pioneira Thomson Learning, 2003.

IRENA. Rethinking Energy 2017: Accelerating the global energy transformation. Abu Dhabi: International Renewable Energy Agency, 2017.

IRENA. REmap: Roadmap for a Renewable Energy Future. 2016 Edition. Abu Dhabi: International Renewable Energy Agency (IRENA), 2016.

MOTTA, S. R. F. Sustentabilidade na construção civil: crítica, síntese, modelo de política e gestão de empreendimentos. 2009. 122f. Monografia (Graduação em Engenharia Civil). Universidade Federal de Minas Gerais, Belo Horizonte, 2009.

SACHS, I. Caminhos para o Desenvolvimento Sustentável. 4. Ed. Rio de Janeiro: Garamond, 2002. 96 p.

SOUSA, Rafaela. Energia Solar. Disponível em:
https://brasilescola.uol.com.br/geografia/energia-solar.htm>. Acesso em: 27 mai. 202I.

TAIPALE, K. Construção, Ambiente e Desenvolvimento Sustentável. Belo Horizonte: Ecolatina, 2007.

TRIGUEIRO, André. Mundo Sustentável 2: Novos rumos para um planeta em crise. I. Ed. São Paulo: Globo, 2012.

VEIGA, José Elo da. Desenvolvimento sustentável: o desafio do século XXI. 2. Ed. Rio de Janeiro: Garamong, 2006.

VG Resíduos. O que fazer com os entulhos gerados na construção?. Disponível em: 〈https://www.vgresiduos.com.br/blog/o-que-fazer-com-os-entulhos-gerados-naconstrucao-civil/>. Acesso em: 27 mai. 2021. 